\title{
REDES SOCIAIS: A INTERAÇÃO PARA ALÉM DA SALA DE AULA
}

\author{
Douglas Vaz ${ }^{1}$ \\ Fabrícia Py Tortelli Noronha ${ }^{2}$ \\ Juliani Menezes dos Reis ${ }^{3}$ \\ Luciana Backes ${ }^{4}$
}

\begin{abstract}
Resumo: Este artigo aborda as relações de interação existentes no contexto das redes sociais, assim como, as mudanças no convívio entre professores e alunos seguindo o fluxo do advento das tecnologias digitais e da sua inserção no ambiente educacional. O surgimento das redes sociais proporciona novos espaços digitais para aprendizagem por meio da interatividade e de interações que vão além da sala de aula. Deste modo, apresenta as interações virtuais realizadas no grupo fechado do Facebook denominado Orientação PPG Educação Unilasalle. O grupo foi criado com o intuito de reunir orientandos e orientadora do Programa de PósGraduação em Educação do Universidade La Salle - UNILASALLE, vinculados à Linha de Pesquisa Culturas, Linguagens e Tecnologias na Educação, no contexto do Grupo de Pesquisa Convivência e Tecnologia Digital na Contemporaneidade (COTEDIC UNILASALLE/CNPq). Considera que o ciberespaço está entrelaçado no espaço geográfico e ambos se confundem nas relações. A Educação está no mesmo fluxo, no qual estudantes e professores compartilham informações cotidianamente por meio de tecnologias digitais. Conclui que as relações em ambiente digital virtual estão sendo configuradas e que as potencialidades das tecnologias digitais devem ser exploradas no meio educacional.
\end{abstract}

Palavras-chave: Interação; Redes sociais; Espaço digital de aprendizagem

\section{SOCIAL NETWORKS: THE INTERACTION BEYOND THE CLASSROOM}

Abstract: This article discusses the relations of interaction that exist in social network context, as well as the changes in teacher and student relationship, taking into account the advent of digital technology and its insertion in educational environment. The emergence of social networks provides new digital spaces for learning through interactivity and through interactions that go beyond the classroom. Thus, this study presents the virtual interactions that were carried out in a closed group on Facebook named Guidance PGP in Education Unilasalle. The group was created in order to gather students with the advisor of Post-Graduate Program in Education of La Salle University - UNILASALLE, bounded to the line of research of Cultures, Languages and Technology in Education, in the context of the search group named Interaction and Digital Technology in Contemporaneity (COTEDIC UNILASALLE/CNPq). This article considers that cyberspace is interlaced with geographic space and they get mixed up in the relations. The Education is in the same flow, in which teachers and students shared information daily through digital technology. Finally, this settles that relations in digital and virtual environment are being configured, and the potentialities of digital technology must be explored in educational environment.

Key-words: Interaction; Social Networks; Digital learning space.

\footnotetext{
${ }^{1}$ Licenciado em Informática pelo Centro Universitário Cenecista de Osório (2012). Especialista em Informática Instrumental para Professores pela Universidade Federal do Rio Grande do Sul (2015). Mestre em Educação pela Universidade La Salle (2017), na linha de pesquisa Culturas, Linguagens e Tecnologias na Educação, (bolsista CAPES/PROSUP). Membro do Grupo de Pesquisa Convivência e Tecnologia Digital na Contemporaneidade COTEDIC UNILASALLE/CNPq. Professor e tutor a distância pelo Instituto Federal de Educação, Ciência e Tecnologia do Rio Grande do Sul - campus Osório/RS. Dirigente de Equipe no Setor Pedagógico da Secretaria de Educação da Prefeitura Municipal de Osório/RS.

${ }^{2}$ Professora do Ensino Básico, Técnico e Tecnológico do Instituto Federal de Educação, Ciência e Tecnologia do Rio Grande do Sul - Câmpus Porto Alegre. Tecnóloga em Processamento de Dados pela Universidade Católica de Pelotas. Pós-graduada em Administração de Marketing pela Universidade Luterana do Brasil. Mestranda no Programa de Pós-Graduação em Educação do Unilasalle.

${ }^{3}$ Bibliotecária na Universidade Federal do Rio Grande do Sul. Especialista em docência no Ensino Superior pela Uniasselvi. Mestre em Educação pela Universidade La Salle (2017). Doutoranda na Linha de pesquisa Culturas, Linguagens e Tecnologias na Educação da Universidade La Salle.

${ }^{4}$ Professora titular da Universidade La Salle - Canoas, Programa de Pós-Graduação em Educação. Graduada em Pedagogia, Habilitação Magistério e Séries Iniciais pela Universidade do Vale do Rio dos Sinos, Especialista em Informática na Educação pela Universidade Federal do Rio Grande do Sul, mestre em Educação pela Universidade do Vale do Rio dos Sinos e doutora em Educação pela Universidade do Vale do Rio dos Sinos e Sciences de l'Education pela Université Lumière Lyon 2.
} 


\section{INTRODUÇÃO}

O acesso cada vez mais rápido às informações, a aceleração do desenvolvimento científico e tecnológico e o novo perfil do profissional para o mercado de trabalho, estão impactando e transformando mundialmente os processos de ensino utilizados pelas instituições acadêmicas. A inserção de novas tecnologias no apoio do ensino, potencializa a interação entre alunos e professores e faz emergir um perfil de aluno mais flexível e adaptado às diversas redes digitais disponíveis atualmente. Dessa forma, observa-se que as instituições acadêmicas, mais do que nunca, estão contextualizando seus processos ao cotidiano dos alunos e da sociedade em geral.

O uso das tecnologias de informação e comunicação no processo de aprendizagem, contribui para a transformação da interação entre aluno/professor na construção do conhecimento e, por consequência, possibilita a interatividade mesmo quando geograficamente distantes e de maneira assíncrona, conforme Castells (2002) num espaço de fluxo e num tempo intemporal.

A configuração estabelecida para a comunicação digital, onde as pessoas não necessitam estar no mesmo lugar para que a comunicação aconteça e é estabelecida de maneira heterárquica e bidirecional, é conhecida como ciberespaço. Para Silva,

Podemos dizer que ciberespaço significa rompimento paradigmático com o reinado da mídia de massa baseada na transmissão. Enquanto esta efetua a distribuição para o receptor massificado, o ciberespaço, fundado na codificação digital permite ao indivíduo teleintrainterante a comunicação personalizada, operativa e colaborativa em rede hipertextual. (SILVA, 2004, p. 5).

Ao potencializar o uso do ciberespaço para a interação da sala de aula presencial $^{5}$, o professor promove a “[...] participação-intervenção, bidirecionalidadehibridação e permutabilidade-potencialidade, aproveitando a confluência oportuna das esferas social, tecnológica e mercadológica." (SILVA, 2014, p. 190). Ao adotar essa prática, o docente possibilita uma construção do conhecimento mútua entre professor e aluno, na qual o aluno pode construir seu próprio percurso de aprendizagem (SILVA, 2014).

Suscita-nos, a partir disso, perguntar como as redes sociais, quando utilizadas como espaço digital de aprendizagem, contribuem para a construção do conhecimento?

${ }^{5} \mathrm{O}$ termo sala de aula presencial é usado conforme Silva (2014), não desconsiderando a discussão proposta por Trein e Backes (2009) sobre a presença on-line. 
Como ocorrem estas relações entre docente e alunos e entre alunos e alunos no grupo analisado? E de que forma, a partir da experiência dos autores, pode-se potencializar o uso das redes sociais para interação da sala de aula presencial?

Este artigo intenta realizar uma reflexão inicial acerca dessas indagações, com o objetivo de criar um ponto de partida para discussões sobre as relações e interações entre alunos e professores em atividades propostas em redes sociais, seus resultados e percepções dos atores envolvidos.

\section{INTERAÇÃO E INTERATIVIDADE NA SALA DE AULA}

Educar na contemporaneidade, utilizando o ciberespaço como forma de comunicação e construção de conhecimento está diretamente atrelado as questões da interação e interatividade no meio educacional. Segundo Salles (2013), interação é uma prática inerente às relações sociais, que sempre se fez presente nos processos educacionais. Para a autora, quando nos referimos às relações professor/aluno e aluno/aluno, por exemplo, temos presente a interação, que ocorre de maneiras diversas. Salles (2013) argumenta que Vygotsky, Piaget e Freire já percebiam a importância das interações fundamentais para o desenvolvimento e a aprendizagem dos sujeitos. No entanto, nem todas as relações são compreendidas como interações. Conforme Maturana (1993) o processo de interação ocorre quando os seres humanos compartilham suas percepções, legitimam as percepções uns dos outros, identificam perturbações, compensam essas perturbações no conversar e transformam-se mutuamente, em congruência com o meio. A partir do desenvolvimento tecnológico e, consequentemente, das transformações das formas de comunicação, emerge o conceito de interatividade.

Quanto à interatividade, Silva (2014, p. 12) afirma ser um

[...] fenômeno da 'sociedade da informação' e manifesta-se nas esferas tecnológica, mercadológica e social”. Na esfera tecnológica, no sentido das tecnologias informáticas conversacionais. Na esfera mercadológica, em razão da busca de diálogo entre produtor-produto-cliente e, na esfera social, onde houve uma ruptura na passividade recepção da informação, dando lugar a uma "crescente autonomia de busca onde cada indivíduo faz por si mesmo. (SILVA, 2014, p. 12).

As novas tecnologias potencializam o grau de interatividade entre usuários e usuário e conteúdo. Permitem, de acordo com Silva (2014), o redimensionamento da mensagem, da emissão e da recepção. A natureza da mensagem pode ser ampliada e reformulada, de acordo com a intenção do leitor. Segundo Silva (2014, p. 14), a 
mensagem torna-se modificável na medida em que responde às solicitações daquele que a consulta, que a explora, que a manipula. Essa possibilidade de interação com o conteúdo e ampliação do conhecimento à vontade do usuário traz inúmeras possibilidades ao ensino, ao desenvolver a autonomia, a autoria e a co-autoria no processo de aprendizagem.

Silva (2014) destaca a comunicação interativa como sendo um importante desafio para a educação contemporânea, de modo a abandonar a educação centrada no paradigma da transmissão de conhecimentos. Nessa perspectiva "[...] se o aprendiz ou usuário produz, usa e controla, ele ganha, já se ele se tornar um usuário pacífico, que apenas fica sentado em frente à tela ou em frente ao professor, ao quadro negro, ele perde, torna-se tudo entediante." (SILVA, 2004, p. 5).

Neitzel et al. comentam que:

[...] a imagem que se colhe hoje da escola é bem diversa; muito se inovou, principalmente no que diz respeito às estratégias de ensino, à relação professor e aluno, aos espaços de aprendizagem, etc. Por meio do Programa Nacional de Tecnologia Educacional (PROINFO), por exemplo, grande parte das escolas públicas brasileiras pode contar com a instalação de salas informatizadas, tornando-se o computador mais uma ferramenta para o ensino. (NEITZEL et al, 2014, p. 833).

É importante destacar que o computador pode auxiliar no processo de ensino e aprendizagem e é necessário que a inserção das novas tecnologias ocorra nas salas de aula para promover experiências inéditas aos alunos, principalmente com o intuito de contextualizar o cotidiano dos alunos em relação aos conhecimentos construídos. Para que isso aconteça, é fundamental que tanto os alunos como professores compreendam as potencialidades das tecnologias digitais e as utilizem em congruência com os conhecimentos. Nesse processo, é necessário que o professor compreenda como ocorre seu próprio processo de aprendizagem a partir das tecnologias digitais a fim de mediar o processo de aprendizagem de seus alunos.

A inserção das tecnologias digitais contribui para transformar nosso modo de viver, conviver e interagir. Desta forma, ocorreram mudanças nos espaços de relacionamento interpessoal e coletivo, nas formas de ler e escrever, no surgimento do letramento digital, mudanças nos processos cognitivos, novas formas de ensinar e aprender, novas formas de acesso à informação e ao conhecimento. Enfim, novos desafios que a sociedade atual proporciona. 
Com o passar do tempo e, em meio ao surgimento de inúmeras inovações tecnológicas, mudanças podem ser observadas. A configuração de um fluxo, às vezes incontrolável; a possibilidade de participação de um número maior de pessoas na produção da informação; a proliferação de informações descartáveis; o desenvolvimento de redes sociais na internet; as mudanças nas formas de relacionamento-entre as pessoas, oscilando entre o duradouro e o efêmero; compartilhamento de informações e produções.

As redes sociais têm um potencial imenso de proporcionar a conexão entre as pessoas e o compartilhamento de informações, conforme sugere Maffesoli (2012), para o bem e para o mal. Nessas conexões ocorrem: a construção de vínculos; interações de natureza virtual; o compartilhamento de informações entre pessoas; as identificações entre diferentes grupos sociais. Vale lembrar também, a facilidade com que as publicações viralizam nas redes sociais alcançando inúmeras pessoas.

\section{REDES SOCIAIS NO MEIO EDUCACIONAL: O USO DO FACEBOOK}

O Facebook é uma mídia social que possibilita a constituição de rede social para estabelecer relacionamentos virtuais, sejam de caráter social, educacional, econômico, religioso ou político, criando um universo em que as fronteiras geográficas já não fazem mais sentido. No Brasil, assim como em diversos países, as redes sociais estão tomando proporções gigantescas. De acordo com Patrício e Gonçalves,

As redes sociais representam uma nova tendência de partilhar contactos, informações e conhecimentos. O Facebook é uma das redes sociais mais utilizadas em todo o mundo para interagir socialmente. Esta interacção surge essencialmente pelos comentários a perfis, pela participação em grupos de discussão ou pelo uso de aplicações e jogos. É um espaço de encontro, partilha, discussão de ideias e, provavelmente, o mais utilizado entre estudantes universitários. (PATRÍCIO; GONÇALVES, 2013, p. 594).

Os jovens, na sua grande maioria, passam boa parte do tempo conectados ao ciberespaço, devido à familiaridade e à presença constante. Esse fato não pode, a priori, ser declarada como bom ou ruim, mas, com certeza, evidencia o potencial agregativo e requer uma investigação mais profunda. Patrício e Gonçalves (2013, p. 593) afirmam que:

Estamos a viver o auge das redes sociais, impulsionado pelo carácter social e pela ideia de partilha, aliado a um ambiente informal, atractivo e catalisador, contribuindo para que cada vez mais jovens adiram a este tipo de software social e, particularmente, à rede social Facebook. 
No contexto educacional, as redes sociais estão cada vez mais presentes no cotidiano dos alunos e professores e essa é uma realidade que a escola pode explorar para contextualizar seus processos, ou seja, pensar nas redes sociais como um novo espaço de aprendizagem e de interação à sala de aula. Para tanto, destacamos o papel mediador do professor explorando as redes sociais em congruência com o conhecimento, estimulando a autoria e co-autoria dos alunos, além de potencializar a interação e a interatividade entre os alunos e entre os alunos e o conhecimento, rompendo os limites territoriais da sala de aula.

Embora o foco principal do Facebook seja o entretenimento, há uma corrente muito forte que defende seu uso no ambiente educacional de modo a potencializar a interação. Minhoto (2012) constatou, ao utilizar os recursos das redes sociais no decurso de uma disciplina, que devido à intimidade dos estudantes com o contexto do Facebook, a interação possibilitou a construção do conhecimento por meio dos processos de aprendizagem.

Um ponto importante relacionado ao uso de redes sociais na educação é a questão da flexibilização proporcionada num espaço de fluxo e num tempo intemporal. Nesse sentido, Alves e Nova destacam que:

[...] pensar o espaço, nos remete a refletir sobre o próprio tempo da aprendizagem. O tempo da escola é único, rígido, quase absoluto. Temos que aprender os mesmos assuntos, durante os dois meses da unidade, e comprovarmos na avaliação. [...]. Essa é a regra, da alfabetização à universidade. (ALVES; NOVA, 2003, p. 42).

A articulação entre a educação presencial e a educação on-line por meio das tecnologias digitais, neste caso o Facebook, para as interações da sala de aula, tendem a proporcionar: rompimento das fronteiras entre a escola e o cotidiano; maior aproximação entre os professores e os alunos; relações de proximidade independente do tempo e do espaço. Esses aspectos podem potencializar o aprendizado, resultando em novas experiências e expectativas nos estudantes em relação à escola, aos conhecimentos e aos significados no cotidiano.

No entanto, alguns aspectos precisam estar em reflexão. As redes sociais disponibilizam um universo imenso de informações, consequentemente: facilidade em dispersão; falta de filtro para pesquisas de conteúdo específico; fluxo intenso determinado pelas mídias de massa. Outro obstáculo para o emprego do Facebook, como um espaço digital de aprendizagem, é a cobertura de internet no Brasil, que além 
de ainda não ser acessível a todos, muitas escolas ainda não possuem acesso ou as que possuem, na maioria das vezes, têm as redes sociais bloqueadas por normativas da própria escola ou do órgão público ao qual estão vinculadas.

$\mathrm{Na}$ figura abaixo, pode-se observar a abrangência da tecnologia $3 \mathrm{G}$ no Brasil, uma das formas de conexão à internet, utilizada principalmente por escolas do campo, onde ainda não está disponível o acesso à internet através do telefone.

Figura 1 - Abrangência da rede 3G no Brasil.

\begin{tabular}{|c|c|c|c|c|c|c|c|c|c|}
\hline Operadora & $\mathbf{2 0 0 8}$ & $\mathbf{2 0 0 9}$ & $\mathbf{2 0 1 0}$ & $\mathbf{2 0 1 1}$ & $\mathbf{2 0 1 2}$ & $\mathbf{2 0 1 3}$ & $\mathbf{2 0 1 4}$ & Out/15 & Nov/15 \\
\hline Vivo $^{1}$ & 314 & 579 & 1.206 & 2.516 & 3.100 & 3.134 & 3.287 & 3.422 & 3.524 \\
\hline Claro $^{1}$ & 284 & 388 & 416 & 745 & 1.152 & 1.374 & 1.768 & 2.158 & 2.262 \\
\hline Tim $^{1}$ & 40 & 57 & 210 & 488 & 593 & 1.000 & 1.336 & 1.646 & 1.741 \\
\hline Oi $^{*}$ & 99 & 168 & 211 & 250 & 529 & 951 & 1.104 & 1.197 & 1.197 \\
\hline Algar $^{*}$ & 16 & 29 & 31 & 32 & 32 & 32 & 35 & 35 & 35 \\
\hline Sercomtel $^{*}$ & - & 2 & 2 & 2 & 2 & 2 & 2 & 2 & 2 \\
\hline Nextel & - & - & - & - & - & 91 & 410 & 410 & 410 \\
\hline $\begin{array}{c}\text { Total } \\
\text { \% do Total de } \\
\text { municipios }\end{array}$ & $\mathbf{8 , 1} \%$ & $\mathbf{1 2 , 8} \%$ & $\mathbf{2 3 , 1} \%$ & $\mathbf{4 7 , 2} \%$ & $\mathbf{5 9 , 2} \%$ & $\mathbf{6 3 , 8} \%$ & $\mathbf{7 0 , 1} \%$ & $\mathbf{7 6 , 6} \%$ & $\mathbf{7 9 , 0} \%$ \\
\hline
\end{tabular}

Fonte: 1 Operadoras * Site das Operadoras.

Nota: Coleta de dados efetuada de 06/Abr a 10/Abr. Os dados nos sites das operadoras podem variar conforme a politica de atualizaçăo das mesmas.

Fonte: Teleco (2015).

Conforme os dados apresentados na figura 1, é possível evidenciar que na maioria das operadoras a expansão da rede $3 \mathrm{G}$ no Brasil teve seu ápice entre os anos de 2011 e 2013 e, após esses anos, algumas mantiveram o crescimento, mas outras praticamente estagnaram, configurando assim mais um obstáculo no acesso à internet. De qualquer forma, independente das adversidades, as redes sociais são uma realidade no nosso cotidiano e não podemos deixar de refletir sobre esse tema.

Então, ao explorar a mídia social no contexto da educação, é possível identificar o uso constante do recurso Grupos, que pode ser usado na criação de espaços fechados onde o conteúdo postado só fica visível aos participantes (FACEBOOK, 2010, on-line).

\section{O recurso Grupos}

[...] permite criar pequenos grupos com pessoas selecionadas para troca privada de informações. Além de fotos e posts, com a novidade, o Facebook irá disponibilizar ferramentas com salas de bate-papo, compartilhamento de documentos e informações por e-mail (FACEBOOK, 2010, on-line). 
Com esse recurso o usuário tem algumas escolhas como manter ou não seus participantes, deixar visível o grupo a qualquer pessoa, possibilitar que qualquer usuário possa fazer parte do grupo, ou ainda, deixar os dados secretos (FACEBOOK, 2010, online). De acordo com essas escolhas, determinamos (professores e alunos) a configuração de espaços virtuais de aprendizagem que promovam a interação e a interatividade entre alunos e professores, onde podem ser criadas discussões pertinentes à sala de aula, além do compartilhamento de ideias e arquivos úteis dentro do contexto de cada disciplina.

\section{GRUPO NO FACEBOOK: ORIENTAÇÃO PPG EDUCAÇÃO UNILASALLE}

Nesta pesquisa, a forma de interação escolhida refere-se ao grupo criado no Facebook denominado Orientação e COTEDIC - PPG Educação UNILASALLE. Este grupo foi criado com o objetivo de reunir orientandos e orientadora do Programa de Pós-Graduação em Educação do Universidade La Salle - UNILASALLE, vinculados à Linha de Pesquisa Culturas, Linguagens e Tecnologias na Educação, no contexto do Grupo de Pesquisa COTEDIC UNILASALLE/CNPq.

Segundo Juliani et al. (2012, p. 3),

O planejamento para a utilização das redes sociais como suporte a educação exige compreender a estrutura e cultura organizacional da instituição de ensino visando adequá-la aos aspectos técnicos das ferramentas existentes para fins educacionais, além de questões de privacidade, ética e políticas de apoio da direção que devem ser contempladas.

Nesse sentido, percebe-se uma aceitação da Instituição pesquisada quanto ao uso do recurso para fins educacionais e a identificação do potencial pedagógico desse recurso por parte da orientadora e dos orientandos, o que pode potencializar o processo de ensino e de aprendizagem. A partir disso, possibilita-se a criação e utilização de novas formas de interação entre professores e alunos geograficamente distantes.

Com o propósito de organizar encontros, leituras, agenda de orientações, sugestões de revistas para publicação de artigos, divulgar eventos da área da Educação, disponibilizar material, compartilhamento de percepções, chamar a atenção para temas relacionados à pesquisa,-entre outros, o grupo funciona como uma forma de incentivar e potencializar a comunicação entre os participantes. Tanto a professora orientadora, quanto os orientandos, podem enviar postagens para todos os membros do grupo, numa relação heterárquica e bidirecional. 
A seguir, a Figura 2 apresenta a interface do grupo capturada no Facebook de modo a ilustrar o seu funcionamento. Quanto à privacidade do grupo, observa-se na imagem abaixo que o mesmo é um grupo fechado, portanto direcionado apenas a um número restrito de estudantes e professores, participantes do grupo de pesquisa e bolsistas de iniciação científica envolvidos no processo de orientação.

Figura 2 - Interface do grupo Orientação e COTEDIC - PPG Educação UNILASALLE

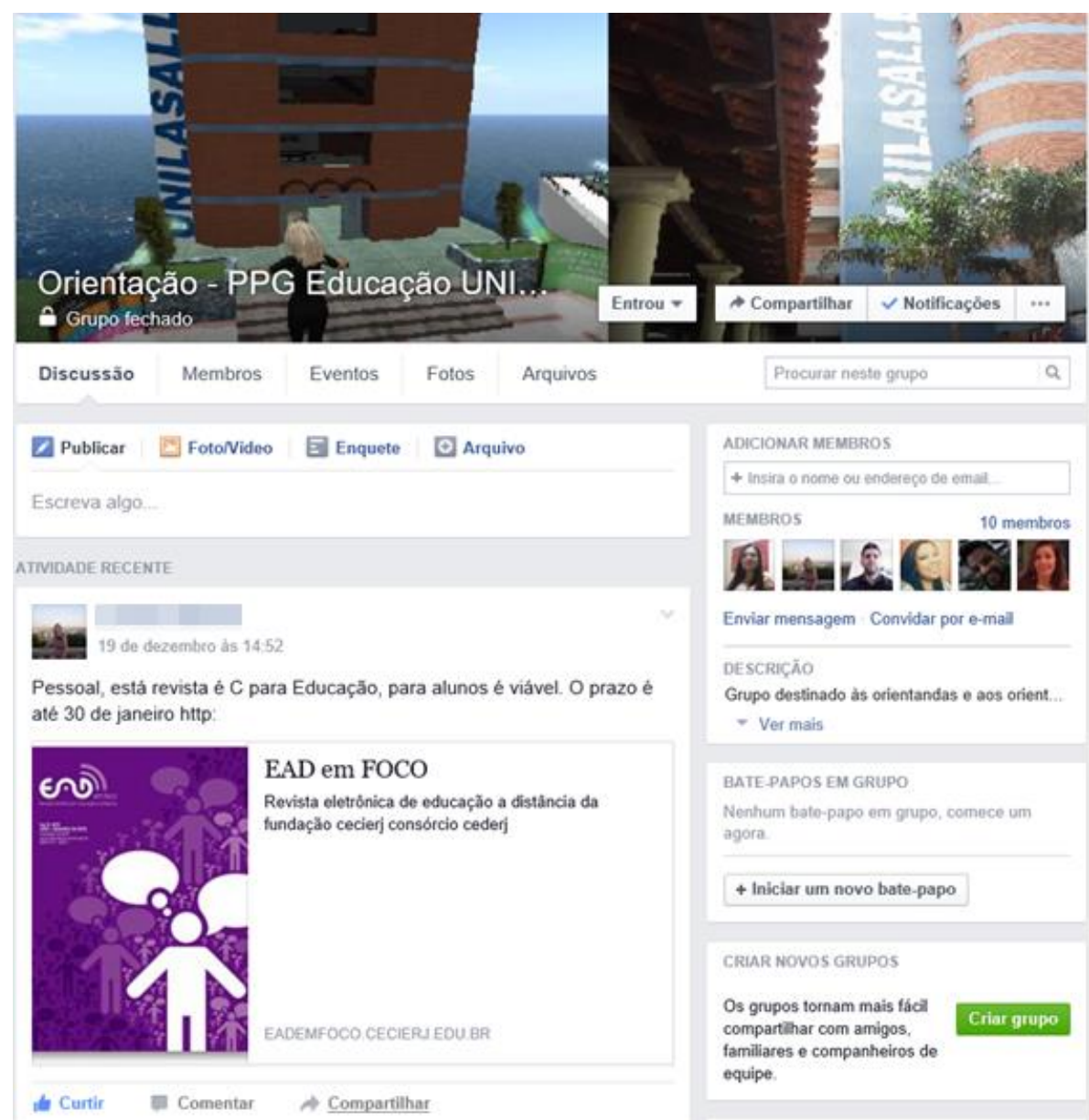

Fonte: Facebook (2015).

O grupo foi criado em março de 2015, pela professora orientadora, como uma das formas de configurar a convivência virtual e potencializar a comunicação relacionada a assuntos pontuais, já que a mesma reside em outro país e precisa utilizar os espaços virtuais para a interação e a presença.

\section{INTERAÇÕES NO FACEBOOK}

Durante o ano de 2015, o grupo Orientação e COTEDIC - PPG Educação UNILASALLE foi utilizado como meio de divulgação de materiais relevantes às pesquisas desenvolvidas pelos orientandos, desde sugestões de leituras, revistas e 
eventos para publicação e debates até assuntos relacionados a agenda de orientações, conforme é apresentado abaixo, na figura 3.

Figura 3 - Exemplo de agenda de orientação

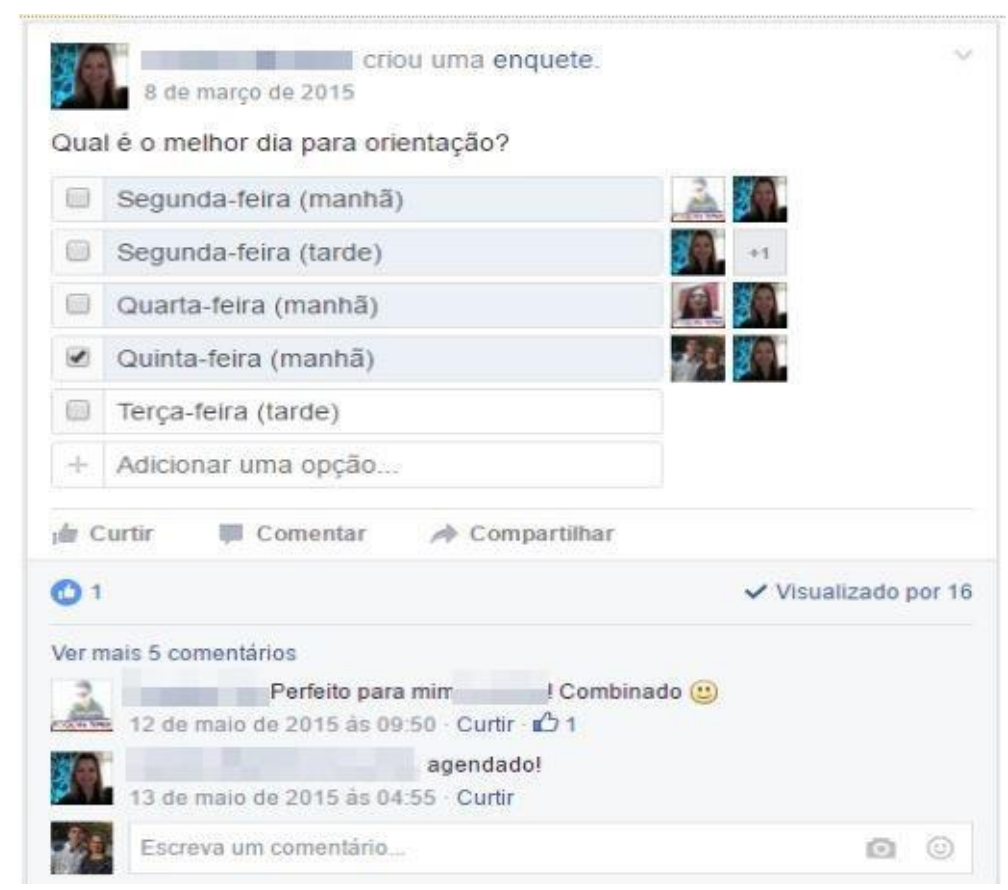

Fonte: Facebook (2015).

Outra questão mencionada anteriormente, que deve ser destacada, remete ao uso do recurso grupos para divulgação de eventos e revistas científicas, assim como a divulgação de trabalhos de autoria dos participantes. Sendo o Facebook uma mídia de fácil e periódico acesso, por parte dos participantes do grupo, garante que as informações sejam visualizadas por todos os integrantes. Um exemplo dessa ação é mostrado abaixo, como mostra a figura 4.

Figura 4 - Divulgação de revista científica através do grupo no Facebook

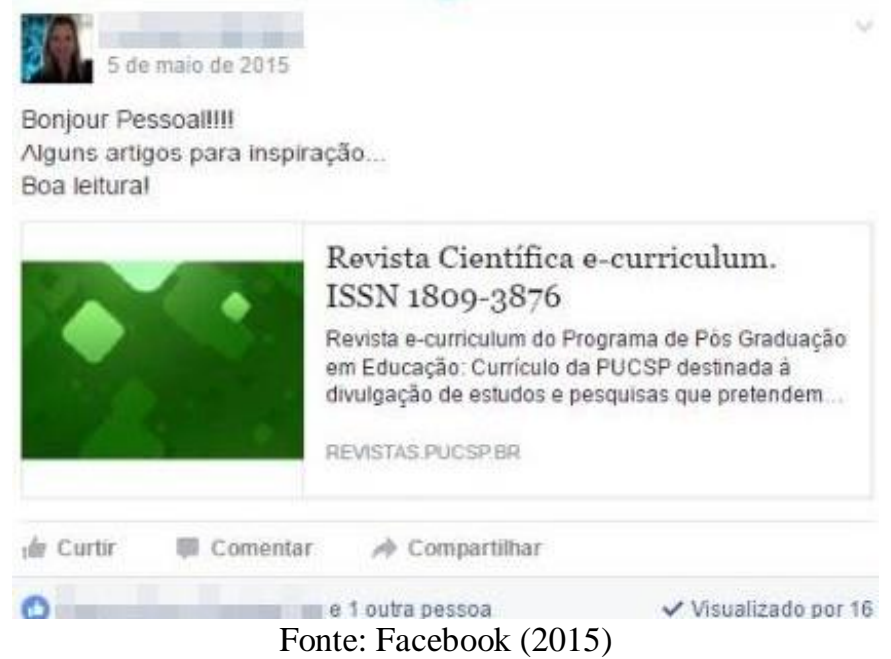


Devido a fácil acessibilidade e por potencializar o compartilhamento de informações e conhecimentos, entre participantes, o Facebook pode ser inserido no contexto do hibridismo tecnológico digital ${ }^{6}$, permitindo a articulação de diferentes tecnologias e plataforma de maneira integrada e articulada. No entanto, nesse compartilhamento, não foi evidenciado a interação entre os participantes, somente o compartilhamento do conhecimento e a legitimação dos participantes por meio do recurso "curtir" e "visualizado".

Percebemos que o processo de interação entre os participantes ocorre com intensidade quando os posts são relacionados ao cotidiano, articulando teoria e prática, como o caso do vídeo "Repórter aplica nas ruas o estilo facebook de curtir a vida", observado na Figura 5

Figura 5 - Interação entre os participantes no Facebook

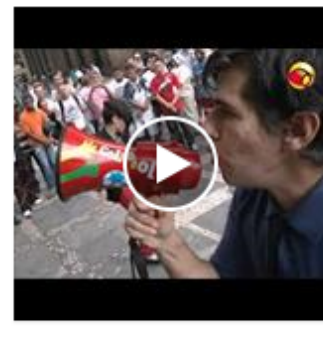

Repórter aplica nas ruas o estilo

Facebook de curtir a vida

Confira o UOL Notícias: noticias.uol.com.br

YOUTUBE.COM

Realmente o face se tornou a Caras digital. Culpa nossa, que
enchemos nossas timelines com inutilidades. Poderiamos ter interações muito
mais produtivas. Na reportagem, percebe-se isso quando o repórter fala no
megafone sobre a sexta feira, o tédio, tr... Ver mais
Descurtir - Responder - 131 - 26 de abril às $12: 44$
superficialidade das amizades no facebook que fazem com que pessoas
tenham muitos amigos sem se quer conhecê-los. Mas, por outro lado, se
soubermos utilizar a ferramenta de forma adequada podemos encontrar
amigos distantes que há tempos não temos notícias, criar vínculos
profissionais e afetivos de acordo com determinadas afinidades.
Curtir - Responder - 26 de abril às $14: 23$
Eu tenho muitos pontos para discutir em relação ao
vídeo. Confesso que o adorei. Como o Facebook, por exemplo, é um rede
social criada basicamente para "'curtir os amigos"', digo isto bem entre aspas.
Mas o adaptamos também para trabalhar com nossa vid... Ver mais
Curtir - Responder - @1 1 - 26 de abril às $15: 38$

Fonte: Facebook (2016)

${ }^{6} \mathrm{O}$ contexto do hibridismo tecnológico digital é configurado, conforme Backes (2015), no cruzamento, na integração e na articulação entre diferentes TD, a partir das ações e interações dos seres humanos. "Portanto, o hibridismo tecnológico digital é criado e recriado a partir do significado atribuído durante a ação, ou seja, no viver e conviver entre os seres humanos em congruência com o espaço" (BACKES, 2015, p. 438). 
Nesse post os participantes manifestam o seu posicionamento, contrário ou a favor ao conteúdo, articulando com as ideias dos colegas, trazendo novas percepções, comentando os conteúdos já estudados e trazendo outras problematizações, enfim, construindo conhecimento na dinâmica do fluxo das redes sociais. Assim, evidenciamos que a mídia social não é utilizada somente para o entretenimento, mas para interações entre todos os envolvidos no processo educacional. Deve, portanto, haver a mediação por parte do professor, que pode problematizar e intensificar estas interações. Nesse sentido, "A participação do professor, definindo as atividades que serão realizadas, publicando conteúdos e acompanhando o grupo criado é decisiva para promover a colaboração e o compartilhamento de conhecimento." (JULIANI et al, 2012, p. 9).

A figura 6 exemplifica como estas interações ocorreram no grupo. Alunos e professores utilizam o ambiente para promover a interação, mediados pela professora orientadora.

Figura 6 - Interação entre professora e estudantes

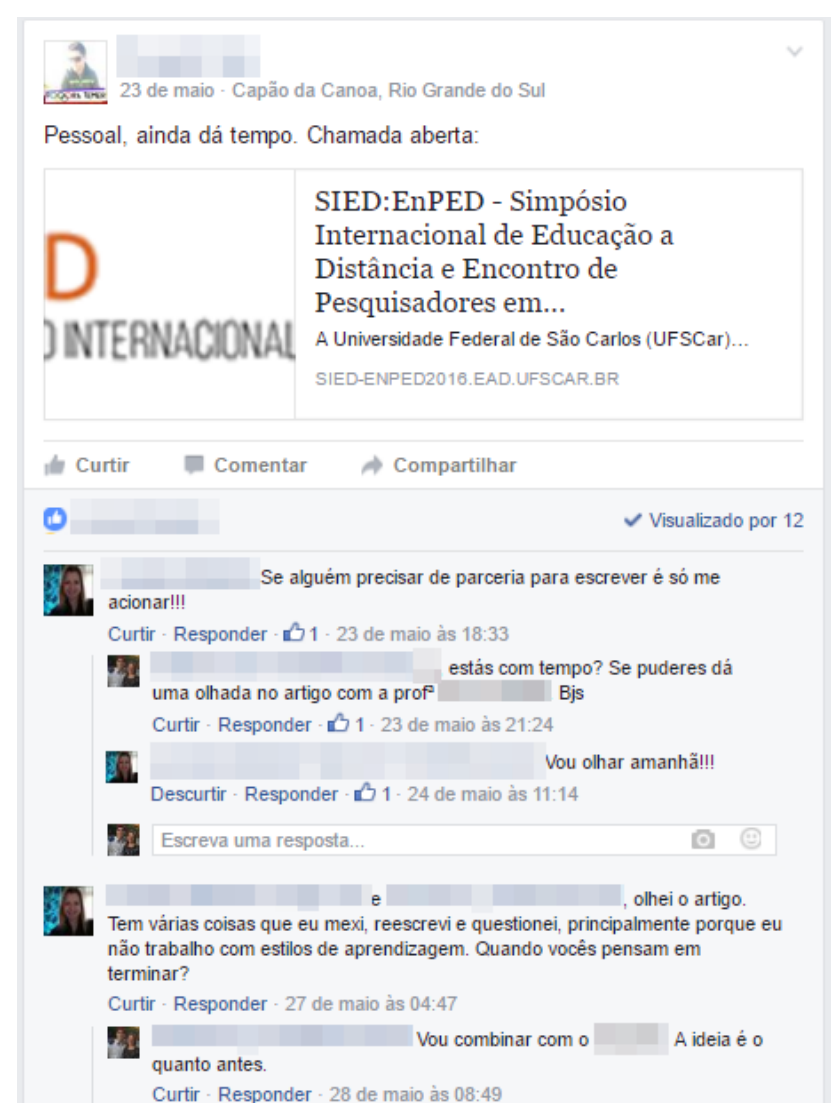

Fonte: Facebook (2016)

Para os autores, integrantes do grupo no Facebook, o mesmo tem sido de grande valia, pois: propicia a comunicação on-line e interativa, torna secundárias as barreiras 
de tempo e de espaço no processo de ensinar e aprender, mistura o cotidiano e o conhecimento, trazendo o mundo para a sala de aula e a sala de aula para o mundo. Desta forma, o grupo tem ampliado os diferentes espaços virtuais para a interação, no contexto do hibridismo tecnológico digital, integrando ao grupo do Facebook: o site ${ }^{7}$ convivência, a sala de videoconferência Adobe Connect, a sala do Moodle, arquivos do drive do Google. As situações relatadas acima mostram que as redes sociais têm um grande potencial para complemento à interação no contexto da educação.

\section{CONSIDERAÇÕES FINAIS}

Com o avanço das tecnologias, as redes sociais fazem, cada vez mais, parte do cotidiano de estudantes e de professores, modificando a comunicação, as formas de compartilhamento de informações, influenciando o modo como a humanidade se relaciona e também sendo modificada e moldada de acordo com as necessidades que vão surgindo com a sua utilização. Contudo, essas relações encontram-se em estágio de configuração, ainda não é natural e evidente para professores e alunos estarem em interação, relacionarem as potencialidades das tecnologias com os conhecimentos a serem construídos e agirem como autores e co-autores do processo de aprendizagem.

Grupos de relacionamentos sempre existiram, a novidade é a virtualidade desses grupos que oportunizam um espaço de convivência virtual flexível tanto no quesito temporal, quanto espacial. Assim, a educação pode e deve apoiar-se em tecnologias que proporcionam essa flexibilidade e fazem parte do convívio diário dos estudantes, de forma a complementar as interações da sala de aula.

Segundo Schlemmer,

[...] num processo de imbricamento, ou seja, o viver e conviver na atualidade ocorrem, cada vez mais, em contextos híbridos e multimodais, onde diferentes tecnologias analógicas e digitais estão presentes, integrando espaços presenciais físicos e online, constituindo assim, novos espaços para o conhecer. É nesses novos espaços que os sujeitos, em movimentos nômades, interagem, constroem conhecimentos, aprendem, o que nos faz pensar que uma nova cultura possa estar emergindo, não dicotômica entre a cultura analógica e a digital, entre imigrantes e nativos digitais, mas sim, uma cultura que coloca esses em relação, numa perspectiva de coexistência. (SCHLEMMER, 2014, p. 10 -11, on-line).

Nessa linha de pensamento, a convivência de natureza digital virtual está sendo configurada no cotidiano, por meio das rotinas diárias, de maneira natural, a fim de que

${ }^{7}$ Disponível em: <www.convivencia.com.br〉. Acesso em: 04 set. 2016. 
o presencial e o on-line não possam mais ser explicados um sem o outro. O ciberespaço está entrelaçado no espaço geográfico de tal forma que ambos se confundem nas relações. Na educação não poderia ser diferente, as relações de aprendizagem nos espaços presenciais podem ser potencializados pelos espaços virtuais e é isso que o grupo criado no Facebook representa para os mestrandos orientados pela professora orientadora, embora as orientações também ocorram por intermédio de outras tecnologias.

\section{REFERÊNCIAS}

ALVES, Lynn; NOVA, Cristiane. (Org.) Educação à Distância: uma nova concepção de aprendizado e interatividade. São Paulo: Futura, 2003.

BACKES, Luciana. O Hibridismo Tecnológico Digital na Configuração do Espaço Digital Virtual de Convivência: Formação do Educador. Inter-ação v. 40, p. 435-457, 2015.

FACEBOOK. Nova ferramenta no Facebook: Grupos. Facebook, 2010. Disponível em: 〈https://www.facebook.com/video/video.php? v=1544398803213〉. Acesso em: 28 dez. 2015.

JULIANI, Douglas Pauleski et al. Utilização das redes sociais na educação: guia para o uso do Facebook em uma instituição de ensino superior. Revista Novas Tecnologias na Educação, v. 10, n. 3, 2012. Disponível em:

<http://www.seer.ufrgs.br/index.php/renote/article/view/36434/23529>. Acesso em: 20 set. 2016.

MATURANA, H. R. Uma nova concepção de aprendizagem. Dois Pontos, Belo Horizonte, v. 2, n. 15, p. 28-35, jan./jul. 1993.

MINHOTO, Paula Maria Lino Veigas. A utilização do Facebook como suporte à aprendizagem da biologia: estudo de caso numa turma do $12^{\circ}$ ano. 2012. Mestrado (Dissertação em Ensino das Ciências)- Escola Superior de Educação, Bragança, 2012. Disponível em: <https://bibliotecadigital.ipb.pt/bitstream/10198/6864/1/PaulaMinhoto_22696.pdf>. Acesso em: 30 out. 2015.

NEITZEL, Adair de Aguiar et al. Desafios da leitura e da escrita em meio digital. Revista Ibero-Americana de Estudos em Educação, v. 9, n. 4, 2014. Disponível em: <http://seer.fclar.unesp.br/iberoamericana/article/view/7282/5317>. Acesso em: 10 nov. 2015 .

PATRÍCIO, Maria Raquel; GONÇALVES, Vitor. Facebook: rede social educativa? ENCONTRO INTERNACIONAL TIC E EDUCAÇÃO, 1., 2010, Lisboa. Anais... Lisboa: Universidade de Lisboa, Instituto de Educação, , 2010. p. 593-598. Disponível 
em: 〈http://bibliotecadigital.ipb.pt/bitstream/10198/3584/1/118.pdf>. Acesso em: 20 set. 2016.

SALLES, Mariluce. Interação e interatividade em educação. [Belo Horizonte]: Educar Brasil: Tecnologia a serviço da educação, [2013]. Disponível em: <http://www.educarbrasil.org.br/publicacoes/interacao-e-interatividade-em-educacao/>. Acesso em: 02 jan. 2016.

SHLEMMER, Eliane. Prefácio. In: PORTO, Cristiane; SANTOS, Edmea (Org.). Facebook e educação: publicar, curtir e compartilhar [online]. Campina Grande: EDUEPB, 2014. Disponível em: <http://static.scielo.org/scielobooks/c3h5q/pdf/porto9788578792831.pdf>. Acesso em: 29 dez. 2015.

SILVA, Marco. Indicadores de Interatividade para o Professor Presencial e Online. Revista Diálogo Educacional, Curitiba, v. 4, n.12, p.93-109, maio/ago. 2004. Disponível em: <www2.pucpr.br/reol/index.php/DIALOGO?dd1=622\&dd99=pdf > Acesso em: 20 de novembro de 2015.

SILVA, Marco. Sala de aula interativa. Rio de Janeiro: Quarter, 2014.

TEIXEIRA. Carlos Alberto. A origem do facebook. O Globo, Rio de Janeiro, 18 de jun. 2012. Disponível em: <http://oglobo.globo.com/sociedade/tecnologia/a-origem-dofacebook-4934191>. Acesso em: 21 de nov. 2015.

TELECO. Municípios cobertos com a tecnologia 3G no Brasil. 2015. Disponível em: <http://www.teleco.com.br/3g_cobertura.asp>. Acesso em: 03 jan. 2016.

TREIN, Daiane; BACKES, Luciana. A Biologia do Amor para uma Educação sem Distância. In: CONGRESSO INTERNACIONAL ABED DE EDUCAÇÃO A DISTÂNCIA, 15., 2009, Fortaleza. Anais... Fortaleza: ABED, 2009. p. 1-10. 
